\title{
A prevenção das infecções sexualmente transmissíveis nos roteiros sexuais de jovens: diferenças segundo o gênero
}

\author{
Prevention of sexually transmitted infections in the sexual scripts \\ of young people: differences according to gender
}

Thelma Spindola (https://orcid.org/0000-0002-1785-5828) ${ }^{1}$

Rosana Santos Costa Santana (https://orcid.org/0000-0002-4342-6322) ${ }^{2}$

Rômulo Frutuoso Antunes (https://orcid.org/0000-0003-2800-5295) ${ }^{3}$

Yndira Yta Machado (https://orcid.org/0000-0003-0692-7299) ${ }^{2}$

Paula Costa de Moraes (https://orcid.org/0000-0001-5482-9293) ${ }^{2}$
${ }^{1}$ Faculdade de Enfermagem, Universidade do Estado do Rio de Janeiro (UERJ). Boulevard 28 de setembro 157, Vila Isabel. 20551-030 Rio de Janeiro RJ Brasil. tspindola.uerj@gmail.com

${ }^{2}$ Programa de Pós-

Graduação em Enfermagem,

UERJ. Rio de Janeiro RJ

Brasil.

${ }^{3}$ Instituto Nacional de

Câncer (INCA). Rio de

Janeiro RJ Brasil.

\begin{abstract}
This study aims to address the vulnerability of young university students to sexually transmitted infections and to identify and analyze the sexual behavior of university students and practices to prevent sexually transmitted infections. A descriptive and qualitative research study conducted in a private university in Rio de Janeiro in 2016, with 30 university students of both genders, aged 18-29 years old. The discursive data were collected by the Focal Group technique and analyzed using the content analysis technique, with the aid of the Nvivo 9.0 software, and anchored in John Gagnon's theory of sexual scripts. The findings denote that university students recognize themselves as a population vulnerable to infections transmitted by unprotected sex. The group has insufficient knowledge about infections and does not use condoms continuously. In the discourses of the university students, it was noticed that the type of affective relationship is determinant for the use (or not) of condoms. Young people believe in the group's invulnerability and therefore assume risky sexual behaviors.
\end{abstract}

Key words Young adult, Vulnerability in health, Sexually transmitted infections, Sexual behavior
Resumo Este estudo tem como objeto a vulnerabilidade dos jovens universitários às infecções sexualmente transmissiveis e como objetivos identificar e analisar o comportamento sexual de estudantes universitários e as práticas de prevenção às infecções sexualmente transmissiviveis. Pesquisa descritiva, qualitativa, realizada em universidade privada no Rio de Janeiro, em 2016, com 30 universitários de ambos os sexos, idades entre 18-29 anos. Os dados discursivos foram coletados pela técnica de Grupo Focal e analisados com emprego da técnica de análise de conteúdo, com auxílio do software Nvivo 9.0, e ancorado na teoria dos roteiros sexuais de John Gagnon. Os achados denotam que os universitários se reconhecem como uma população vulnerável às infecções transmitidas pelo sexo desprotegido. O grupo apresenta insuficiência de conhecimentos sobre as infecções e não usa preservativos de modo contínuo. Percebeu-se, nos discursos dos universitários, que o tipo de relacionamento afetivo é determinante para uso (ou não) do preservativo. Os jovens acreditam na invulnerabilidade do grupo e, por conseguinte, assumem um comportamento sexual de risco.

Palavras-chave Adulto jovem, Vulnerabilidade em saúde, Infecções sexualmente transmissiveis, Comportamento sexual 


\section{Introdução}

As Infecções Sexualmente Transmissíveis (IST) são frequentes e recorrentes, consideradas um problema de saúde pública em todo o mundo. Causam grandes efeitos na saúde sexual e reprodutiva e são um dos cinco principais motivos de procura da população para o atendimento em saúde ${ }^{1}$. A epidemiologia das IST tem evidenciado que cerca de $25 \%$ das infecções são diagnosticadas em indivíduos com idade inferior a 25 anos. Fatores biológicos, culturais e socioeconômicos corroboram para a elevação da taxa de incidência das IST ${ }^{2}$.

No que concerne às IST/HIV/aids, existem situações que fragilizam ou tornam a pessoa vulnerável ao adoecimento, como a adoção de práticas sexuais inseguras. Tais práticas são decorrentes de um conjunto de fatores e variáveis presentes em sua vida particular e coletiva, bem como pelas condições socioambientais em que ele vive, além das respostas que as instituições público-sociais podem dar às suas necessidades de saúde ${ }^{3}$. As características inerentes ao público jovem podem produzir dinâmicas que conduzam a comportamentos que resultarão num conjunto de experiências de grande intensidade, que podem (ou não) envolver o consumo de substâncias psicoativas e a adoção de comportamentos de risco com práticas sexuais inseguras ${ }^{4}$.

O ser humano é dependente da socialização e a prática sexual está associada à complexidade dinâmica e sócio-histórica dos indivíduos ${ }^{5}$. $\mathrm{O}$ comportamento humano é influenciado por construtos sociais e pela cultura. A teoria dos roteiros sexuais, elaborada pelo sociólogo John Gagnon, assevera que a conduta sexual é determinada pela história e pela cultura, sendo uma elaboração interpretada e reinterpretada ao longo do ciclo de vida dos indivíduos. A sexualidade é adquirida e organizada pela estrutura social e pela cultura. Os comportamentos sexuais, compreendidos como "roteiros sexuais", estão inseridos em cenários culturais, roteiros interpessoais e roteiros intrapsíquicos ${ }^{6}$.

Nesse contexto, torna-se relevante identificar as condutas sexuais dos jovens, as quais, integradas ao contexto social, permitem vislumbrar a influência na saúde sexual, minimizando ou ampliando a vulnerabilidade do grupo frente às IST. Assim, foram delimitados como objetivos do estudo: identificar e analisar o comportamento sexual de estudantes universitários e as práticas de prevenção às infecções sexualmente transmissíveis.

\section{Metodologia}

Trata-se de um estudo descritivo com abordagem qualitativa fundamentada na teoria dos roteiros sexuais. Este estudo é parte integrante da pesquisa "Sexualidade e vulnerabilidade dos jovens em tempos de Infecções Sexualmente Transmissíveis", vinculada ao Programa de Pós-Graduação de Enfermagem da Universidade do Estado do Rio de Janeiro.

Os participantes do estudo foram 30 jovens universitários, sendo 15 do sexo masculino e 15 do feminino, contemplando a homogeneidade dos grupos focais. Os critérios de inclusão definidos foram: ser aluno regularmente matriculado em curso de graduação da universidade, com idade entre 18 e 29 anos. Este critério foi empregado, tendo em vista o Estatuto da Juventude, que dispõe sobre direitos e diretrizes das políticas/programas públicas(os) de juventude aos indivíduos com idade entre 15 e 29 anos $^{7}$.

O cenário do estudo foi uma instituição de ensino superior privada, localizada na cidade do Rio de Janeiro. Os dados foram coletados segundo a técnica de Grupo Focal (GF), no período de junho a novembro de 2016. Como estratégia para alcance dos objetivos da pesquisa, foi elaborado um roteiro com temas a serem discutidos com os estudantes - sexualidade; condutas sexuais/gênero, prevenção de IST - que tinham aderência ao objeto deste estudo. Foram realizados três GF com a participação de 10 estudantes (de ambos os sexos), uma moderadora e duas observadoras. Os encontros duraram cerca de 120 minutos.

Após a coleta de dados, os GF e o diário de campo foram transcritos na íntegra para a construção do corpus, que foi formatado de modo a tornar o material compreensível, retirando gírias e vícios de linguagem, expressões não verbais e palavras de uso coloquial inadequadas para a pesquisa científica.

$\mathrm{Na}$ análise dos dados, empregou-se a técnica de análise do conteúdo, análise temático-categorial $^{8}$ operacionalizada com auxílio do software Nvivo 9.0. Foi empregada a forma manual de codificação, cujos fragmentos de texto eram recortados e agrupados em Nodes que representam as categorias. Esta pesquisa trabalhou com três grandes Nodes: Sexualidade; Condutas Sexuais dos Jovens e Prevenção de IST. Os fragmentos de texto foram denominados UR e selecionados à luz do referencial teórico, assim como a definição dos Nodes.

Os resultados da análise foram expressos em classes discursivas, que contêm temas identifica- 


\section{Resultados}

A caracterização dos participantes evidenciou que houve maior representatividade de jovens com idades entre 18 e 24 anos, ou seja, jovens-jovens. A maioria (28) não tem filhos e reside com os pais (25). No que concerne à idade e status de relacionamento, a metade (13) dos jovens-jovens é solteiro e apenas um adulto-jovem é casado. Um quantitativo maior de universitários (16) declarou-se solteiro, ou seja, não tinha namorado ou companheiro e (9) tinham namorado/companheiro fixo.

A análise temática dos dados resultou na identificação e codificação de 487 unidades de registro (UR) que respondiam às questões da pesquisa, que foram distribuídas em temas/unidades de significação.

\section{Categoria: Infecções Sexualmente Transmissíveis - os jovens se preocupam com a prevenção?}

Essa categoria apresenta as práticas de prevenção das Infecções Sexualmente Transmissíveis adotadas pelos jovens, o cuidado com a saúde sexual e a prevenção das IST. Representa $30 \%$ do corpus investigado e está estruturada em duas subcategorias: 1) Preocupação dos jovens com a prevenção das Infecções Sexualmente Transmissíveis - conhecimentos e receios; 2) Uso do preservativo nos relacionamentos afetivos dos jovens.

Subcategoria 1: Preocupação dos jovens com a prevenção das Infecções Sexualmente Transmissíveis - conhecimentos e receios

Os dados discursivos denotam o conhecimento dos universitários sobre as IST e modos de transmissão e seus receios quanto à exposição às IST. Têm representatividade de $15 \%$ do total do corpus estudado. Como indicador de conhecimento dos participantes foram consideradas as informações que tinham sobre as infecções e as corretas formas de transmissão das IST mais reconhecidas pelo grupo:

Eu acho que a principal, a que a pessoa tem mais medo é o HIV, sifilis, gonorreia. (Participante 1)

Mononucleose, a do beijo. (Participante 2)

Cancro Mole, sifilis. (Participante 3)

HPV. (Participante 4)

Sabe também o que acontece? A gente sabe mais da aids, da sifilis e das outras a gente não conhece. E tem gente não cuidando da doença, é porque não tem informação. (Participante 5)

$\mathrm{Na}$ concepção dos participantes, a transmissão das IST pode ocorrer de diversas maneiras: na relação sexual, no sexo oral, contato sanguíneo, em feridas abertas e alicates de unhas:

Transando. (Participante 6)

Sexo oral. (Participante 7)

Eu acho que é mais o contato sanguineo que você pega por seringa. (Participante 8)

Ou até ferimentos abertos. (Participante 9)

Eu posso pegar no oral, mesmo não tendo uma penetração com pênis. Um curativo no amigo, às vezes, sei lá. Botou a mão, foi cortar a unha com o mesmo alicate e pegou hepatite. (Participante 10).

Outro participante acredita que a abstinência sexual evitaria a exposição:

[...] na verdade, a infecção sexualmente transmissível não se transmite só através do sexo, como os dedos, por exemplo, você já tem riscos. A única forma de você não pegar uma DST, se Deus quiser, é não transar de jeito nenhum. (Participante 11)

Alguns referiram que só tomam conhecimento de uma determinada infecção ou doença quando atinge alguém próximo ou ele mesmo:

A maioria das pessoas, elas só conhecem quando elas veem alguém ou elas mesmo [com alguma infeç̧ão]. A maior parte da população tem aids $e$ não sabe. Eu não tinha noção de doença até o meu melhor amigo descobrir que o namorado tinha HIV e passou para ele, e ele tinha dezesseis anos quando ele descobriu [...] um choque, porque na época que isso aconteceu não tinha propaganda, não tinha muito. Não se dizia, não falava muito sobre HIV. (Participante 10)

Os receios e ansiedades frente às IST, especialmente o HIV, foram explicitados nas descrições de alguns universitários:

Eu acho que a principal, o que a pessoa tem mais medo é o HIV. (Participante 1)

Aids é uma doença como qualquer outra doença, mas é uma doença que mata e você precisa se preservar. Se você não se cuida, você morre. (Participante 10)

Outros estudantes revelaram, contudo, que não tinham receio da aids:

Eu acho que hoje em dia as doenças estão sendo mais permitidas porque os jovens ficam "Ah, mas 
tem tratamento, não preciso me preocupar com isso". Se eu pegar aids, eu tomo coquetel, eu não vou morrer. (Participante 12)

Alguns jovens exteriorizaram preocupação em reduzir a vulnerabilidade às IST, pelo uso contínuo de preservativo, e verbalizaram que é preciso se proteger:

Você vê o antes e depois de chegar nesse susto [de pegar uma doença], sem camisinha eu não transo mais. (Participante 12)

Porque hoje em dia tem essa ideia de que sexo não é uma coisa ruim e você só precisa se prevenir, se proteger. (Participante 13)

Os estudantes revelaram ter consciência dos riscos e formas de prevenção às IST:

Muitas pessoas possuem a informação e gostam da sensação de perigo. Têm aqueles que conhecem [as formas de contrair IST] e não estão nem aí. (Participante 14)

"Ah, amiga, sumi com aquele bofe e aí não teve jeito, acabou rolando e tal”. Ai eu falo, "mas e aí, se preveniu e tal?", "ah, amiga a gente nem lembrou disso", sabe como é que é, né, estava meio alterado, mas eu acho que não tem problema não, não é a primeira vez que isso acontece [transar sem preservativo] e não aconteceu nada. Por que vai acontecer agora? (Participante 15)

A procura pela realização de exames preventivos foi descrita pelos jovens:

Então eu e minha namorada, a gente está há dois anos junto, e a gente costuma fazer pelo menos uma vez por ano os exames para prevenir. Mesmo num relacionamento, você tem que se cuidar e tem que saber. (Participante 10)

\section{Subcategoria 2: Uso de preservativos nos} relacionamentos afetivos dos universitários

Essa categoria representa $15 \%$ do total do corpus estudado e descreve o uso do preservativo masculino e feminino pelos estudantes, o uso conforme o tipo de parceria sexual, a negociação para uso do preservativo e fatores envolvidos na não adesão ao preservativo:

Normalmente, eu não uso camisinha. (Participante 13)

É chocante, mas eu, com 20 anos na cara, fui descobrir que eu não sabia colocar uma camisinha masculina. (...) eu tive que aprender! (Participante 16)

Tem homens que já chegam e falam: eu não uso camisinha, sei lá por que, mas eu broxo. (Participante 14).

A camisinha me incomoda. (Participante 17).

O homem não curte e não vai curtir aquela mulher com aquilo [o preservativo feminino]. (Participante 11).
A maioria dos universitários informou que, numa relação casual ou esporádica, é necessário (e mais frequente) o uso do preservativo:

Agora, relações esporádicas, eu não curto transar na pele [sem preservativo] com todas as mulheres, homens e animais que eu ver na minha frente. (Participante 11)

Se você pega uma pessoa completamente desconhecida, é mais provável que você use o preservativo porque você não sabe o passado sexual dela e não se sente confiante. (Participante 1)

O tipo de relacionamento afetivo e a confiança (ou não no parceiro) determinam o uso (ou não) do preservativo, na concepção dos universitários:

Você vai deixar de usar a camisinha quando começar a se relacionar [relacionamento fixo] porque é uma prova da confiança. O deixar de usar a camisinha se torna extremamente importante como se fosse mais um passo da relação. (Participante 11)

Não tem muito por que usar [o preservativo], tendo em vista que os dois são saudáveis e confiam um no outro. (Participante 18)

Eu acho que com a questão da confiança 'ah, já estou casado, já acostumei a transar com uma [só mulher]. (Participante 3)

Tem caso de amigos meus que namoram há anos e não usam a camisinha há muito tempo porque a garota toma pílula todo mês. (Participante 6)

No Quadro 1 estão expostos os comportamentos sexuais femininos e masculinos no grupo estudado.

\section{Discussão}

Pode-se perceber, nos achados, que alguns universitários possuíam conhecimento insuficiente sobre as IST e que grande parte teve dificuldade em nomear as infecções que conheciam. O conhecimento é maior em relação às infecções mais difundidas, como o HIV/aids, que é divulgada em diversos meios de comunicação. As demais, como a tricomoníase e outras não mencionadas pelo grupo, ao contrário. A mononucleose, citada por um estudante, não é considerada uma IST, é uma virose conhecida como a "doença do beijo". Em se tratando de estudantes universitários, nota-se que alguns apresentam conhecimento abaixo do esperado e verbalizam o contato em curativos e feridas como uma possibilidade de transmissão de IST. A falta de informação, portanto é um elemento que contribui para a vulnerabilidade individual dos universitários. 
Quadro 1. O uso de preservativos nos roteiros sexuais dos estudantes universitários. Rio de Janeiro, 2020.

\begin{tabular}{|c|c|}
\hline \multicolumn{2}{|c|}{ Universitários homens } \\
\hline Comportamento sexual com parcerias fixas & Comportamento sexual com parcerias casuais \\
\hline Nem sempre usam preservativo & $\begin{array}{l}\text { Usam preservativo com maior frequência, por } \\
\text { acreditarem ser necessário }\end{array}$ \\
\hline $\begin{array}{l}\text { Têm confiança no parceiro, acreditam que o } \\
\text { conhecem bem, que é saudável }\end{array}$ & $\begin{array}{l}\text { Não conhecem bem o parceiro e, por isso, desconfiam } \\
\text { da sua condição de saúde }\end{array}$ \\
\hline $\begin{array}{l}\text { Deixa de usar o preservativo se a parceira toma pílula } \\
\text { anticoncepcional }\end{array}$ & $\begin{array}{l}\text { Usam preservativo mesmo se souberem que a parceira } \\
\text { usa anticoncepcional }\end{array}$ \\
\hline \multicolumn{2}{|l|}{ Desconhecem e desaprovam o preservativo feminino } \\
\hline \multicolumn{2}{|c|}{ Na presença de álcool/e ou drogas, podem não usar o preservativo } \\
\hline \multicolumn{2}{|c|}{ Podem não usar o preservativo porque não gostam e porque acreditam que impede o prazer sexual } \\
\hline \multicolumn{2}{|c|}{ Universitárias mulheres } \\
\hline Comportamento sexual com parcerias fixas & Comportamento sexual com parcerias casuais \\
\hline $\begin{array}{l}\text { Têm confiança no parceiro porque acreditam que } \\
\text { o conhecem bem; por isso, nem sempre usam o } \\
\text { preservativo. }\end{array}$ & $\begin{array}{l}\text { Não conhecem bem o parceiro e, por desconhecerem a } \\
\text { sua condição de saúde, usam sempre preservativo. }\end{array}$ \\
\hline $\begin{array}{l}\text { Usam o preservativo (masculino) no início do } \\
\text { relacionamento com maior frequência. Depois, por } \\
\text { confiarem, no parceiro substituem por outro método } \\
\text { (contraceptivo) }\end{array}$ & $\begin{array}{l}\text { Usam preservativo com maior frequência em todas as } \\
\text { relações sexuais, não confiam nas parcerias sexuais. } \\
\text { Usam sempre preservativo (masculino) }\end{array}$ \\
\hline \multicolumn{2}{|c|}{ Não costumam usar preservativo feminino por desconhecer. Acreditam que o parceiro vai criticar e não gostar } \\
\hline \multicolumn{2}{|c|}{ Na presença de álcool/e ou drogas, podem não usar o preservativo } \\
\hline
\end{tabular}

Considerando a vulnerabilidade dos jovens às IST, muitos pesquisadores têm se debruçado para verificar o conhecimento desse grupo a respeito do tema. Pesquisa que avaliou o conhecimento sobre as doenças sexualmente transmissíveis (DST) e o comportamento sexual de 532 adolescentes no Rio Grande do Sul constatou que 78\% das meninas e $89,3 \%$ dos meninos tinham conhecimento adequado sobre as doenças e que os meninos conheciam mais as DST que as meninas $(\mathrm{p}=0,002)^{9}$. Estudo com 768 universitários, realizado no Rio de Janeiro, analisou a relação dos aspectos sociais dos jovens com o conhecimento acerca das formas de transmissão das infecções sexualmente transmissíveis, e constatou que os estudantes possuíam conhecimento abaixo da média em relação às IST. Estudantes do sexo feminino, casados ou que viviam juntos, que tinham filhos e cursavam a área da saúde possuíam mais conhecimento, sendo estatisticamente significativo $(\mathrm{p}=<0.05)^{10}$. Na Malásia, estudo com 700 universitários da área da saúde e não saúde constatou que $86,6 \%$ já tinham ouvido falar das DST. O HIV/aids teve a maior representatividade no grupo $(83,6 \%)$, enquanto a clamídia (26\%) e tricomoníase $(21 \%)$ são pouco conhecidas ${ }^{11}$.
Investigações têm demonstrado que existem falhas no processo de prevenção das IST pela falta de visibilidade das infecções, formas de transmissão, incidência, sintomas e consequências para a saúde. As IST acarretam incertezas e dúvidas entre os jovens que não conseguem identificar o perigo que os circunda ${ }^{12}$. Estudo que adotou a escala de conhecimentos, atitudes e práticas (CAP) para avaliação sinaliza que os jovens, ainda, apresentam práxis duvidosas, contraditórias e tabus sobre determinadas IST, principalmente na dimensão conhecimento e prática ${ }^{3}$. Estes fatores contribuem para aumentar a vulnerabilidade da população jovem às IST.

O HIV/aids é a infeção mais conhecida e temida por alguns participantes. $\mathrm{O}$ medo do vírus e da doença (aids) foi manifestado no grupo, especialmente, entre os jovens com orientação sexual homoafetiva, pelo estigma da aids. A aids é uma doença, ainda nos tempos atuais, percebida como a que atinge pessoas de comportamentos transgressores, moral e socialmente reprováveis. Estudo $^{13}$ abordou o valor negativo que as pessoas ainda têm em relação ao HIV/aids, ancorados na ideia imagética do início da epidemia, na década de 1980. Os elementos negativos da doença foram 
abordados em pesquisa que revelou o sentimento de tristeza e medo associado com a morte ${ }^{14}$.

No contexto das IST, acrescenta-se que na década de 1990, a aids foi entendida como uma doença e a apreensão da patologia superou o campo da saúde, sendo manifestada a preocupação com as condutas sexuais da sociedade, nos espaços sanitário e político. Desse modo, houve uma mobilização epidemiológica frente ao "sexo de risco" e ao uso do preservativo nos intercursos sexuais como hábito saudável ${ }^{5}$.

O medo da morte é algo real para alguns participantes deste estudo. Sabe-se que ser portador do HIV, atualmente, não é sinônimo de morte. A qualidade de vida das pessoas soropositivas para o HIV melhorou de modo expressivo, mas é indispensável o seguimento do tratamento adequado. O comportamento dos jovens em relação ao HIV pode estar associado ao distanciamento do problema por não terem visualizado as pessoas morrendo, como ocorreu nos anos 1980 e 1990, e, também, pela falsa sensação de invulnerabilidade que acreditam ter. Autores ${ }^{3}$ sinalizam que, embora se reconheça como alta a vulnerabilidade dos jovens brasileiros, este grupo tem uma baixa percepção de risco. A aids, hoje, é entendida como uma doença crônica e, em caso de exposição ao HIV, a pessoa exposta pode utilizar o coquetel (medicamentos antirretrovirais). Pesquisa ${ }^{15}$ constatou mudanças nas representações sociais da aids para os profissionais de saúde. Elementos que integravam o núcleo central da representação migraram para a periferia, como o termo morte; elementos centrais, anteriormente negativos, passaram a positivos após a transição do conceito de doença fatal para uma doença crônica. Houve uma diminuição na importância da morte, no processo de transformação das representações sociais da aids, para os profissionais de saúde. As relações humanas constroem um simbolismo complexo, capaz de ampliar o conhecimento associado à síndrome e às práticas dos profissionais de saúde ${ }^{15}$.

A postura dos participantes de descuido para com a saúde sexual é preocupante, considerando que poucos relataram a realização de exames preventivos. Nos grupos focais, percebeu-se que as universitárias demonstravam maior preocupação com os cuidados com a saúde, em comparação com os homens. O Brasil tem apresentado aumento da prevalência de HIV entre os mais jovens, principalmente entre homens que fazem sexo com homens $(\mathrm{HSH})^{16}$. Sabe-se que a prevenção das IST está diretamente relacionada com a prática do sexo seguro e a superação dos contextos de vulnerabilidade. Autores ${ }^{3}$ sinalizam que é importante fortalecer os programas e as políticas públicas de atenção à saúde dos jovens, sendo necessário conhecer as vulnerabilidades e os determinantes sociais.

A inexistência de coesão das práticas sexuais referidas pelos universitários e as práticas de prevenção adotadas foram observadas. Assim, embora os participantes descrevessem preocupações com a saúde e a prevenção das IST, assumiam comportamentos sexuais inadequados e ficavam expostos às situações de risco. Nesse contexto, a existência de serviços para o aconselhamento e assistência à saúde sexual e reprodutiva do público jovem seriam oportunos ${ }^{17}$.

A educação sexual no ambiente escolar pode ser um recurso para a desconstrução de informações equivocadas sobre a sexualidade. É uma concepção contemporânea de apreensão social relativa às experiências sexuais na adolescência, que se tornaram mais frequentes e independentes das influências morais, com o passar do tempo ${ }^{5}$.

No que concerne ao uso do preservativo, sabe-se que os jovens costumam usar com maior frequência nas primeiras relações sexuais. $\mathrm{O}$ preservativo é um recurso que contribui para a prevenção das IST, mas muitos participantes afirmaram não gostar e não ter o hábito de usar esse método preventivo nas relações sexuais. Estudo ${ }^{18}$ demonstra que jovens do sexo masculino se preocupam menos com a saúde sexual em comparação ao sexo feminino. Jovens homens, na faixa etária de 15 a 24 anos, procuram pouco as Unidades Básicas de Saúde para realizar testes para detecção de IST, como HIV, sífilis e hepatites B e C; já entre as jovens mulheres, esse cuidado é mais frequente. A dificuldade de acesso dos jovens às unidades de saúde, a baixa promoção da saúde do homem, a pouca visibilidade e limitações encontradas na Política Pública de Saúde do Homem podem justificar esse comportamento masculino.

Muitos participantes do gênero masculino revelaram não gostar de usar o preservativo porque incomoda ou aperta, são alérgicos ao látex, dificulta a manutenção da ereção e diminui o prazer. Sabe-se que as dificuldades para o uso do preservativo estimulam a prática do sexo inseguro. Pesquisa realizada com 1208 jovens constatou que $40 \%$ dos participantes acreditam que em relacionamentos estáveis não é necessário o uso do preservativo e $36,1 \%$ não usaram preservativo na última relação sexual ${ }^{3}$. Estudo avaliou a percepção de jovens heterossexuais sobre o uso do preservativo com parceiros casuais e constatou 
como vantagens a prevenção de IST e da gravidez indesejada. Como desvantagens, a qualidade do sexo e sensações físicas (diminuição da sensibilidade e ereção) ${ }^{19}$.

O preservativo feminino não é empregado pelas universitárias entrevistadas. Quando fazem uso de preservativo, preferem usar o masculino, por sua praticidade. Muitos participantes referiram desconhecimento sobre o manuseio do preservativo feminino, além da dificuldade de acesso, e, por isso, preferem usar o preservativo masculino. Pesquisa constata que o preservativo feminino tem baixa adesão devido à falta de informações adequadas e acessibilidade; já a camisinha masculina é mais divulgada e acessível ao público em geral $^{20}$. Considerando o risco de exposição às IST, a utilização do preservativo feminino deve ser estimulada e valorizada. Para a incorporação do uso habitual desse recurso, é necessário que existam espaços para ter acesso ao insumo, ter informações adequadas ao nível de instrução das pessoas, além da troca de experiências para que possam exercer sua autonomia e cidadania, com ações sistematizadas das políticas públicas existentes.

Sabe-se que muitos jovens não usam preservativos, ou usam esporadicamente, e ficam expostos à prática do sexo inseguro. Os participantes verbalizaram que o preservativo masculino é mais adotado e melhor aceito com parceiros casuais. Estudo ${ }^{18}$ com indivíduos de 15 a 64 anos, evidenciou que a maioria dos jovens faziam uso do preservativo de modo contínuo nas relações sexuais, diferente dos adultos, que desprezavam o uso do dispositivo. Pesquisa ${ }^{21}$ com conscritos do exército brasileiro verificou que o uso do preservativo foi menor com os parceiros fixos $(34,5 \%)$ e maior com os parceiros menos estáveis $(45,6 \%)$.

Os relacionamentos casuais são roteiros ocorridos em apenas um único encontro. Tem diferentes graus de variáveis de intimidade $\mathrm{e}$, quando ocorre o coito, pode ser considerado "sexo acidental ou encontro de uma noite". Já nos relacionamentos mais sólidos, como namoro ou união estável/casamento, é um momento com começo, meio e fim, socialmente roteirizados ${ }^{6}$.

$\mathrm{Na}$ perspectiva dos entrevistados, o tipo de relacionamento afetivo é determinante para aderir (ou não) ao uso preservativo nas relações sexuais. Os roteiros sexuais (parceria fixa ou casual), portanto, vão orientar a adoção (ou não) de práticas preventivas. A confiança no parceiro substitui a prevenção de uma IST, acrescentam os universitários, como mencionado pelo participante 11: "Você vai deixar de usar a camisinha quando começar a se relacionar [relacionamento fixo] porque é uma prova da confiança”. Os jovens acreditam na fidelidade dos parceiros e alegam que os conhecem (que é uma pessoa saudável). Por isso, deixam de usar práticas de proteção. Jovens casados, ou que vivem em união com outro parceiro, são mais vulneráveis por usarem menos preservativo e buscarem menos informação sobre DST, em comparação aos solteiros ${ }^{3}$. Investigando mulheres soropositivas para o HIV, autores enfatizam que nos relacionamentos estáveis as mulheres parecem não perceber a possibilidade de exposição às IST/HIV/aids, considerando que, no imaginário feminino, a infecção, ainda, é associada à prostituição, promiscuidade e aos relacionamentos extraconjugais ${ }^{20}$.

Os roteiros sexuais são estruturados em três níveis distintos e envolvem o aspecto psíquico, a interação e a cultura, ressaltando-se que a conduta sexual é mais influenciada pelo meio social que impulsionada por instintos biológicos ${ }^{6}$. Os níveis de roteirização nas condutas sexuais de jovens universitários, portanto, perpassam por aspectos intrapsíquicos, interpessoais e o cenário cultural que dialogam entre si, sendo possível a sua reestruturação para promover cenários positivos em relação às IST.

Os roteiros intrapsíquicos são os julgamentos que o indivíduo faz com ele próprio de acordo com as expectativas sociais e culturais de comportamento. Os roteiros interpessoais podem ser descritos como uma representação de si norteado pelo espelhamento implícito do outro, sendo a manutenção ritualizada de atos. É a maneira de agir e de ser de uma pessoa sendo conectada ao que os demais esperam e/ou praticam. Tem ação sob o nível da interação social, e estabelecem que o indivíduo adquire as normas com base nos padrões de comportamento socialmente aceitos. Os cenários culturais são aqueles evidentemente ligados aos determinantes ou guias da vida coletiva e estabelecem os papéis sociais, em geral ${ }^{6}$.

A dinâmica que engloba esses três níveis descritos se relaciona diretamente nas dimensões históricas, culturais e individuais do sujeito, e se traduz na experiência que cada pessoa pode ter em seus roteiros sexuais. Considerando que a juventude é um momento de experimentação da sexualidade e de estruturação da identidade, se entende que, no sentido cultural, os preconceitos e as crenças organizam as possibilidades sexual -afetivas dos jovens.

Percebeu-se, também, que os jovens universitários, quando deixavam de usar o preservativo com os parceiros, não se colocavam na posição 
de indivíduo vulnerável às IST. Estudo ${ }^{22}$ avaliou a representação social de jovens universitários sobre a vulnerabilidade e concluiu que os jovens visualizam a vulnerabilidade como sendo do "outro", principalmente quando possuem parceira(o) fixa(o), ou não apresentam comportamentos promíscuos ou possam ser contaminados por alguma IST.

A teoria dos roteiros sexuais pode auxiliar a compreensão de fenômenos importantes, como a epidemia de aids, considerando que o autor tem uma concepção distinta das teorias que tomam a biologia como referência para explicações sobre a sexualidade. As motivações da sexualidade, assevera o autor, são eminentemente sociais e culturais, e não estão condicionadas à biologia e tampouco às determinações psíquicas ${ }^{6}$.

Nos relacionamentos estáveis, como namoro e casamento, os jovens costumam substituir o preservativo masculino pelo anticoncepcional hormonal oral (pílula), demonstrando que se preocupam com uma gravidez não planejada, mas não com as IST. Estudo com universitários constatou diferença na proporção do uso de preservativos entre os que namoram e os casados ou com companheiro e sinaliza que, nessas relações, possam ocorrer peculiaridades, inclusive para a adoção de comportamentos protetivos ${ }^{23}$. A negociação do preservativo nos relacionamentos afetivos, muitas vezes, esbarra em obstáculos. Nas relações com parceiros fixos, como no namoro e casamento, sabe-se que é difícil para a mulher negociar o uso do preservativo e esse é um assunto delicado para ser abordado entre os casais.

Ao longo da vida de uma pessoa os roteiros podem variar conforme o número de vezes em que ocorreu o intercurso sexual e as práticas decorrentes desses encontros (conjunto roteirizado de comportamentos que vai do beijo ao coito) e o quantitativo de parceiros de cada pessoa ${ }^{6}$. As condutas sexuais podem ser descritas como roteiros sexuais que se renovam a cada ato sexual ou parceiro, e estão vinculados aos sentimentos de desejo e prazer do jovem.

A mulher, na visão dos universitários, é o principal agente para a negociação do uso do preservativo nos relacionamentos. A comunicação entre os casais, entretanto, pode ser um obstáculo para a negociação. Assim, apesar da crença que a mulher tem no seu papel de mediadora nos relacionamentos, sabe-se que esse assunto é delicado e podem emergir situações como a associação à infidelidade por uma das partes. Para as mulheres, $o$ fato de o preservativo masculino ser mais divulgado representa uma desvantagem, já que necessitam negociar com o parceiro, que é quem vai fazer uso do recurso, para cuidar do seu corpo. $\mathrm{O}$ fato de as mulheres desconhecerem tecnologias para a prevenção e os estigmas relacionados ao HIV/aids faz com que a infecção não seja uma preocupação para as mulheres, especialmente entre as que exercem a sexualidade numa matriz normativa ${ }^{24}$.

Os participantes verbalizaram que a relação do casal pode ser estremecida por uma possível desconfiança de fidelidade do parceiro, caso um deles solicite o uso do preservativo para a prevenção de IST. Dentre os nove universitários que namoravam, quatro referiram não ter dificuldade para negociar o uso do preservativo com os parceiros sexuais. A existência e manutenção de um canal de comunicação entre os casais é um elemento imprescindível para a compreensão e superação de dificuldades. Para a harmonia sexual dos casais, é importante que compartilhem opiniões e respeitem um ao outro na tomada de decisão. A manutenção do diálogo e a convivência harmoniosa nas relações afetivas assegura a autonomia no exercício da sexualidade.

\section{Conclusão}

O conhecimento sobre as Infecções Sexualmente Transmissíveis, os modos de transmissão e receios quanto à exposição às infecções foram percebidos nos discursos dos universitários. A insuficiência de conhecimento sobre as infecções, apresentada por alguns, que reconhecem somente aquelas mais divulgadas nas mídias e meios acadêmicos, como o HIV, corroboram para o aumento da vulnerabilidade individual do grupo frente às IST.

No que concerne à prevenção das IST, entendem que está diretamente relacionada à prática do sexo seguro, com o uso contínuo do preservativo, e na superação dos contextos de vulnerabilidade, tendo consciência de que precisam querer se cuidar e preservar a saúde. Percebeu-se que o comportamento de risco, exteriorizado nas práticas sexuais dos estudantes, era dissonante de seus discursos e não acompanhava as medidas de prevenção adotadas pelo grupo.

A busca periódica para atendimento de saúde e a realização de exames preventivos (como o exame ginecológico) foi mais frequente entre as universitárias, que demonstraram preocupação com os cuidados com a saúde sexual. Já os estudantes do sexo masculino informaram buscar a realização de testes para detecção do HIV e outras IST. 
Os universitários revelaram que não faziam uso do preservativo de modo regular, porque não gostavam e por falta de hábito. Para os homens, o preservativo masculino dificultava a manutenção da ereção, diminuía o prazer sexual e alguns mencionaram alergia ao látex. As universitárias descreveram dificuldades no manuseio do preservativo feminino, que tinha aparência estética desagradável, e preferiam usar o preservativo masculino. Os estudantes usavam preservativos de modo esporádico (ou não usavam) e ficavam expostos aos riscos do sexo desprotegido, o que é um agravante para a saúde, já que algumas IST são silenciosas.

Nos discursos dos universitários, a confiança nas parcerias sexuais substitui o uso dos preservativos por outros métodos, como os contraceptivos orais, acreditando na fidelidade dos casais.
Pode-se perceber que os roteiros sexuais dos relacionamentos estáveis tornam os jovens mais vulneráveis às IST, tendo em vista que ficam mais expostos se comparados àqueles que se relacionam com parceiros casuais.

Acredita-se que a identificação dos elementos psicossociais que favorecem a maior vulnerabilidade dessa população deve ser relevante para a construção de uma cultura de prevenção. A educação em saúde do grupo jovem poderia ser estimulada e desenvolvida no ambiente universitário, contribuindo para a diminuição das vulnerabilidades desse grupo. $\mathrm{O}$ estudo teve como limitação a realização com estudantes de uma única instituição. Seria oportuno que fosse replicado em outros ambientes, com outras metodologias, embora os resultados apresentados sejam consoantes a outras investigações com jovens universitários.

\section{Colaboradores}

T Spindola: concepção e delineamento do artigo, análise e interpretação dos dados, redação do artigo e revisão crítica. RSC Santana: análise e interpretação dos dados, redação do artigo e revisão crítica. RF Antunes: concepção do artigo, análise e interpretação dos dados, redação do artigo e revisão crítica. YY Machado: análise e interpretação dos dados e redação do artigo. PC Moraes: análise e interpretação dos dados e redação do artigo. 


\section{Referências}

1. World Health Organization (WHO). Sexually transmitted infections (STIs) [Internet]. 2015 [acessado 2020 jan 20]. Disponível em: http://www.who.int/mediacentre/factsheets/fs110/en/.

2. Brasil. Ministério da Saúde (MS). Secretaria de Vigilância em Saúde. Boletim Epidemiológico - Aids e DST. Brasília: MS; 2016.

3. Fontes MB, Crivelaro RC, Scartezini AM, Lima DD, Garcia ADA, Fujioka RT. Fatores determinantes de conhecimentos, atitudes e práticas em DST/aids e hepatites virais, entre jovens de 18 a 29 anos, no Brasil. Cien Saude Colet 2017; 22(4):1343-1352.

4. Spindola T, Oliveira CSR, Santana RSC, Sodré CP, André NLNO, Brochado EJ. Práticas sexuais, conhecimento e comportamento dos universitários em relação às Infecções Sexualmente Transmissíveis. Rev Fund Care Online 2019; 11(5):1135-1141.

5. Bozon M. Sociologia da sexualidade. Rio de Janeiro: Editora FGV; 2004.

6. Gagnon JH. Uma interpretação do desejo: ensaios sobre o estudo da sexualidade. Rio de Janeiro: Garamond; 2006.

7. Brasil. Lei no 12.852 , de 05 de agosto de 2013. Institui o Estatuto da Juventude e dispõe sobre os direitos dos jovens, os princípios e diretrizes das políticas públicas de juventude e o Sistema Nacional de Juventude - SINAJUVE. Diário Oficial da União 2013; 5 ago.

8. Bardin L. Análise de conteúdo. Lisboa: Edições 70; 2011.

9. Genz N, Meincke SMK, Carret MLV, Corrêa ACL, Alvez CN. Doenças sexualmente transmissíveis: conhecimento e comportamento sexual de adolescentes. Texto Contexto Enferm 2017; 26(2):e5100015.

10. Fonte VRF, Spindola T, Francisco MTR, Sodré CP, André NLNO, Pinheiro CDP. Jovens universitários e o conhecimento acerca das infecções sexualmente transmissíveis. Esc Anna Nery 2018; 22(2):e20170318.

11. Folasayo AT, Oluwasegun AJ, Samsudin S, Saudi SNS, Osman M, Hamat RA. Assessing the knowledge level, attitudes, risky behaviors and preventive practices on sexually transmitted diseases among university students as future healthcare providers in the central zone of Malaysia: a cross-sectional study. Int J Environ Res Public Health 2017; 14(2):E159.

12. Carvalho PMRS, Guimarães RA, Moraes PA, Teles SA, Matos MA. Prevalência de sinais e sintomas e conhecimento sobre doenças sexualmente transmissíveis. Acta Paul Enferm 2015; 28(1):95-100.

13. Angelim RCM, Pereira VMAO, Freire DDA, Brandão BMGDM, Abrão FMDS. Representações sociais de estudantes de escolas públicas sobre as pessoas que vivem com HIV/aids. Saude Debate 2017; 41(112):221229.

14. Bezerra EO, Pereira MLD, Maranhão TA, Monteiro PV, Brito GCB, Chaves ACP, Sousa AIB. Análise estrutural das representações sociais sobre a aids entre pessoas que vivem com vírus da imunodeficiência humana. Texto Contexto Enferm 2018; 27(2):e6200015.

15. Oliveira DC. Construção e transformação das representações sociais da aids e implicações para os cuidados de saúde. Rev Lat-Am Enferm 2013; 21(n. esp.):276-286.
16. Brasil. Ministério da Saúde (MS). Secretaria de Vigilância em Saúde. Boletim Epidemiológico de HIV Aids 2019. Brasília: MS; 2019.

17. Oliveira ACGDP, Caramelo F, Patrício M, Camarneiro AP, Cardoso SM, Pita JR. Impacto de um programa de intervenção educativa nos comportamentos sexuais de jovens universitários. Rev Enferm Ref 2017; (13):71-82.

18. Pinto VM, Basso CR, Barros CRDS, Gutierrez EB. Fatores associados às infecções sexualmente transmissíveis: inquérito populacional no município de São Paulo, Brasil. Cien Saude Colet 2018; 23(7):2423-2432.

19. Davis KC, Schraufnagel TJ, Kajumulo KF, Gilmore AK, Norris J, George WJ. A qualitative examination of men's condom use attitudes and resistance: "It's just a part of the game". Arch Sex Behav 2014; 43(3):631643.

20. Lourenço GO, Amazonas MCLA, Lima RDMD. Nem santa, nem puta, apenas mulher: a feminização do HIV/aids e a experiência de soropositividade. Sex Salud Soc 2018; (30):262-281.

21. Damacena GN, Szwarcwald CL, Motta LR, Kato SK, Adami AG, Paganella MP, Pereira GFM, Sperhacke RD. Retrato do comportamento de risco dos conscritos do Exército brasileiro à infecção pelo HIV por macrorregiões brasileiras, 2016. Rev Bras Epidemiol 2019; 22(1):E190009.

22. Costa SP, Silva TB, Rocha TA, Guisande TCCA, Cardoso AM, Gomes JL, Guisandre MTCR. Saberes e representações de vulnerabilidade para DST/HIV/AIDS por jovens universitárias. Id On Line 2016; 10(31):2542.

23. Moreira LR, Dumith SC, Paludo SS. Condom use in last sexual intercourse among undergraduate students: how many are using them and who are they? Cien Saude Colet 2018; 23(4):1255-1266.

24. Sordi BA, Malcher CD, Lima MLC, Moreira ACG. A feminização da aids: efeitos da moral médica. Polemica 2015; 15(2):13-28.

Artigo apresentado em 30/04/2020

Aprovado em 09/04/2021

Versão final apresentada em 11/04/2021

Editores-chefes: Romeu Gomes, Antônio Augusto Moura da Silva 